\title{
Working Memory Capacity Predicts Dopamine Synthesis Capacity in the Human Striatum
}

\author{
Roshan Cools, ${ }^{1,2 *}$ Sasha E. Gibbs, ${ }^{1 *}$ Asako Miyakawa, ${ }^{1}$ William Jagust, ${ }^{1,3}$ and Mark D’Esposito ${ }^{1}$ \\ ${ }^{1}$ Helen Wills Neuroscience Institute, University of California, Berkeley, California 94720-3190, ${ }^{2} \mathrm{~F}$. C. Donders Centre for Cognitive Neuroimaging, Radboud \\ University Nijmegen, 6500 HB, Nijmegen, The Netherlands, and ${ }^{3}$ Lawrence Berkeley National Laboratory, Berkeley, California 94720
}

Evidence from psychopharmacological research has revealed that dopamine receptor agents have opposite effects on cognitive function depending on baseline levels of working memory capacity. These contrasting effects have been interpreted to reflect differential baseline levels of dopamine. Here we demonstrate for the first time that working memory capacity as measured by listening span predicts dopamine synthesis capacity in the striatum, indicating that subjects with low working memory capacity have low DA synthesis capacity in the striatum, whereas subjects with high working memory capacity have high DA synthesis capacity in the striatum.

Key words: dopamine; working memory; striatum; listening span; PET; cognition; prefrontal cortex

\section{Introduction}

The mesocorticolimbic dopamine (DA) system is known to play a role in cognitive processes, including working memory (Brozoski et al., 1979). This form of memory refers to the active "online" maintenance and manipulation of information over a short interval of time (Goldman-Rakic, 1995) and has been associated most commonly with the prefrontal cortex (PFC) (Fuster, 1989). Evidence from studies with experimental animals suggest an "inverted U"-shaped function, by which both insufficient as well as excessive levels of DA $D_{1}$ receptor stimulation in the PFC impairs working memory (Sawaguchi and Goldman-Rakic, 1991; Williams and Goldman-Rakic, 1995; Arnsten, 1998). This is evidenced, for example, by work with experimental animals showing that $D_{1}$ receptor stimulation improved poor working memory performance that was accompanied by low in vivo DA levels in the PFC, but impaired good performance that was accompanied by high DA levels in the PFC (Granon et al., 2000; Floresco and Phillips, 2001; Phillips et al., 2004). A similar mechanism may exist for the striatum (Frank and O'Reilly, 2006; Pezze et al., 2007), which is strongly connected with the PFC in socalled frontostriatal circuits (Alexander et al., 1986). An inverted U-shaped relationship between baseline DA levels and cognitive performance may also underlie contrasting effects of dopaminergic drugs in humans (Cools et al., 2001, 2007; Mattay et al., 2003). Thus, psychopharmacological studies in humans have shown that the effects of the administration of DA receptor agents on cognition (as well as serum prolactin levels) depend on baseline levels of working memory capacity as measured with the listening

\footnotetext{
Received Oct. 1, 2007; revised Dec. 17, 2007; accepted Dec. 17, 2007.

This work was supported by National Institutes of Health Grants MH63901, NS40813, DA02060, and AG027984. We are grateful to Susan Landau for assistance with data analysis.

${ }^{*}$ R.C. and S.E.G. contributed equally to this work.

Correspondence should be addressed to Roshan Cools at the above address. E-mail: roshan.cools@fcdonders.ru.nl.

D01:10.1523/JNEUROSCI.4475-07.2008

Copyright $\odot 2008$ Society for Neuroscience $\quad$ 0270-6474/08/281208-05\$15.00/0
}

span test (Daneman and Carpenter, 1980; Salthouse and Babcock, 1991), with diametrically opposite effects in subjects with high and low listening span (Kimberg et al., 1997; Mattay et al., 2000; Kimberg and D'Esposito, 2003; Gibbs and D'Esposito, 2005, 2006; Frank and O'Reilly, 2006; Cools et al., 2007). Specifically, administration of DA receptor agonists improves cognitive performance [e.g., set shifting (Kimberg et al., 1997; Frank and O'Reilly, 2006; Cools et al., 2007), working memory updating (Mehta et al., 2000; Frank and O'Reilly, 2006) and working memory retrieval (Gibbs and D'Esposito, 2005)] in subjects with low span, but impairs performance in subjects with high span. Based on evidence from studies with experimental animals (Williams and Goldman-Rakic, 1995; Zahrt et al., 1997; Arnsten, 1998; Phillips et al., 2004), these contrasting effects of DA agents have been interpreted to reflect differential baseline levels of DA, with low span corresponding to low baseline levels of DA and high span corresponding to high baseline levels of DA. This hypothesis is consistent with a number of positron emission tomography (PET) studies that have demonstrated associations between (working) memory performance and the degree of DA receptor binding (Bäckman et al., 2000; Aalto et al., 2005). However, there is currently no data in direct support of the hypothesis that listening span predicts baseline DA levels. The present study fills this gap by demonstrating that working memory capacity as measured with the listening span test predicts DA synthesis capacity in the striatum.

\section{Materials and Methods}

Subjects. The University of California Berkeley Committee for the Protection of Human Subjects approved the procedures, which were in accord with the Helsinki Declaration of 1975. Twenty-five (three male) subjects who previously participated in a pharmacological study on the effects of bromocriptine (Cools et al., 2007) were invited to participate in this study. Eleven female subjects (mean age, 22.2; 2 SD) accepted and were eligible to participate in the PET scan (for additional demographic details, see Table 1). The relationship between the drug effects on the tasks administered in that previous study and baseline DA synthesis will 
Table 1. Neuropsychological data

\begin{tabular}{lcc}
\hline Test & Low-span & High-span \\
\hline Listening span* & $2.8(0.6)$ & $4.0(0.0)$ \\
Age & $21.5(0.8)$ & $23.0(2.8)$ \\
NAART errors & $13(1.4)$ & $11(3.2)$ \\
BDI & $2.5(2.0)$ & $6.2(4.0)$ \\
Forward digit span & $8.8(1.5)$ & $10.4(1.7)$ \\
Spatial span & $20.6(3.2)$ & $22.6(0.9)$ \\
WCST, \% perseverative errors & $6.8(2.1)$ & $7.0(0.8)$ \\
WCST, \% nonperseverative errors & $8.8(4.2)$ & $5.8(2.1)$ \\
Letter fluency & $43.0(8.6)$ & $48.8(7.1)$ \\
MoCA & $28.0(2.0)$ & $28.8(1.1)$ \\
Barratt score & $60.2(15.4)$ & $74.0(12.6)$ \\
\hline
\end{tabular}

*Significantly different between the low- and high-span groups. There were no significant differences in performance on any of the background measures. NAART, North American Adult Reading Test (Nelson, 1982); BDI, Beck Depression Inventory (Beck et al., 1961); WCST, Wisconsin Card Sorting Test (Grant and Berg, 1948); MoCA, Montreal Cognitive Assessment (Nasreddine et al., 2005).

be reported in a separate publication (R. Cools, M. J. Frank, S. E. Gibbs, A. Miyakawa, W. Jagust, and M. D'Esposito, unpublished observation).

Subjects were screened for psychiatric and neurological disorders, gave written informed consent, and were compensated for participation. Exclusion criteria were any history of cardiac, hepatic, renal, pulmonary, neurological, psychiatric, or gastrointestinal disorders, an episode of loss of consciousness, use of psychotropic drugs, sleeping pills, and heavy marihuana use ( $>10$ times in a lifetime).

As part of the previous study, subjects completed a battery of neuropsychological tests, which included (1) the listening version (Salthouse and Babcock, 1991) of a reading span task modeled after that used by Daneman and Carpenter (1980), (2) the North American Adult Reading Test (Nelson, 1982), (3) the Beck Depression Inventory (Beck et al., 1961), (4) the forward digit span, (5) the forward and backward spatial span (Corsi block-tapping test) (Milner, 1971), (6) the Wisconsin Card Sorting Test (WCST) (Grant and Berg, 1948), (7) a paper and pen version of the Stroop task (Stroop, 1935), (8) a letter fluency task (Benton, 1968), (9) the Montreal Cognitive Assessment (MoCA) (Nasreddine et al., 2005) (analogous to the Mini Mental State Examination, to assess mild cognitive impairment), and (10) the Barratt Impulsiveness Scale (Patton et al., 1995) (Table 1).

Listening span test. Working memory capacity was investigated with the listening version (Salthouse and Babcock, 1991) of a reading span task modeled after that used by Daneman and Carpenter (1980). Subjects listened to sets of two to seven sentences and completed a written factual verification question for the content of each sentence. After the last sentence of each set, subjects recalled the final word of each sentence in the order in which they were presented. The span represents the maximum number of sentences performed correctly on at least two out of three trials (for more details, see Salthouse and Babcock, 1991).

PET imaging. Subjects underwent a single positron emission tomography scan with the tracer $6-\left[{ }^{18} \mathrm{~F}\right]$ fluoro-L-m-tyrosine (FMT). The tracer was synthesized with a modification of the procedure as previously reported (Namavari et al., 1993). FMT is comparable with the more widely used $\left[{ }^{18} \mathrm{~F}\right]$ fluorodopa, with the exception that it is not a substrate for $\mathrm{O}$-methylation and therefore provides higher signal-to-noise images. Because it tracks decarboxylase activity it is an index of presynaptic dopamine synthesis capacity, that is, about processes that occur in striatal terminals of midbrain dopamine neurons (DeJesus et al., 1997; Jordan et al., 1997). All subjects were scanned $\sim 60 \mathrm{~min}$ after administration of an oral dose of $2.5 \mathrm{mg} / \mathrm{kg}$ of the peripheral decarboxylase inhibitor carbidopa to increase brain uptake of the tracer. Participants were positioned on the scanner bed with a pillow and an elastic band to comfortably restrict head motion. Images were obtained on a Siemens (Erlangen, Germany) ECAT EXACT HR scanner in three-dimensional (3D) acquisition mode. A 10 min transmission scan was obtained for attenuation correction, then $\sim 2.5 \mathrm{mCi}$ of FMT were subsequently injected as a bolus in an antecubital vein and a dynamic acquisition sequence in 3D mode was obtained: $4 \times 1 \mathrm{~min}, 3 \times 2 \mathrm{~min}, 3 \times 3 \mathrm{~min}$, and $14 \times 5 \mathrm{~min}$ for a total of 89 min of scan time.

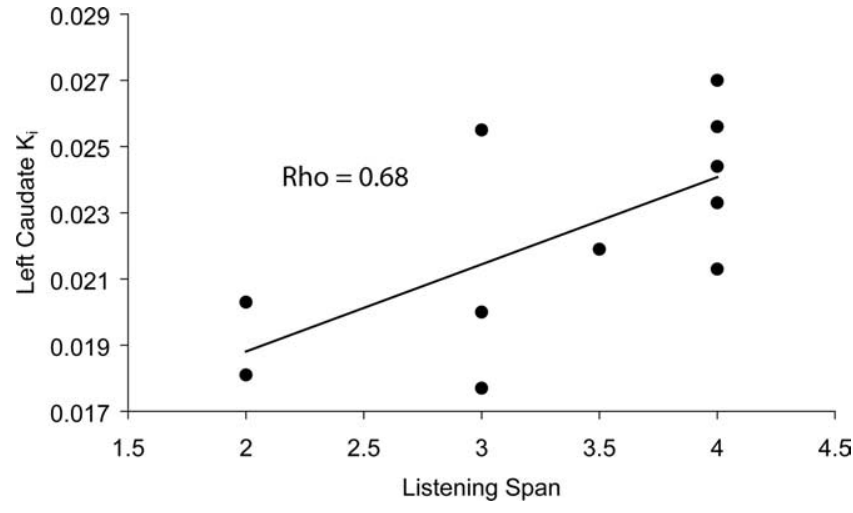

Figure 1. The correlation between listening span and $K_{i}$ values from the left caudate nucleus.

PET image analysis. Data were reconstructed using an ordered subset expectation maximization algorithm with weighted attenuation, an image size of $256 \times 256$, and six iterations with 16 subsets. A Gaussian filter with $6 \mathrm{~mm}$ full-width at half-maximum was applied, with a scatter correction. Images were evaluated for subject motion and realigned as necessary using algorithms implemented in SPM2.

PET images were then coregistered to each individual's highresolution MP-FLASH (magnetization-prepared fast low-angle shot three-dimensional sequence $)(0.875 \times 0.875 \times 1.54 \mathrm{~mm})$ obtained during the previous magnetic resonance imaging (MRI) study using a 12parameter affine algorithm implemented in SPM2. This permitted the use of the high-resolution MRI image for anatomical verification of the localization of functional PET ROIs. Bilateral cerebellar ROIs were used as a reference ROI in conjunction with ROIs in striatum and a simplified reference tissue model with a graphical analysis approach (Patlak and Blasberg, 1985; Lammertsma and Hume, 1996). This leads to an influx constant $K_{i}$, which reflects regional FMT uptake scaled to the volume of distribution in the reference region.

To test hypotheses about DA differences in subregions of the striatum, we defined ROIs in the right and left caudate and putamen. An axial image representing the sum of the last four emission scans of the PET scanning session ( $4 \times 5 \mathrm{~min}$ frames) was coregistered to the highresolution magnetic resonance (MR) scan. ROIs were drawn on these images (Wang et al., 1996; Volkow et al., 1998), using the atlas of Talairach and Tournoux (1988) to delineate the caudate and putamen. Regions were drawn on data in native space to preserve differences in tracer uptake caused by anatomical variability between subjects. We have previously demonstrated the ability to draw ROIs with high inter-rater reliability (Klein et al., 1997). The Patlak model was fitted with dynamic data from each ROI from 24 to $89 \mathrm{~min}$, when the regression is highly linear $(r>0.99)$.

Spearman $r$ correlations were calculated between listening spans (obtained as part of the previous study) and $K_{i}$ values from each of the four ROIs (obtained as part of the current PET study). In addition, one-way ANOVA was used to compare $K_{i}$ values directly between high- and lowspan subjects. To this end, we divided subjects into a high-span and low-span subgroups according to previous studies (Kimberg et al., 1997; Gibbs and D'Esposito, 2005, 2006); subjects with a span of four or greater $(n=5)$ were considered high-span subjects, whereas those with a span less than four $(n=6)$ were considered low-span subjects.

\section{Results}

There was a significant positive correlation between listening span and $K_{i}$ values from the left caudate nucleus $\left(r_{(11)}=0.68\right.$, $p_{\text {two-tailed }}=0.022$ ) (Fig. 1). This correlation remained significant after correction for age $\left(r_{(8)}=0.65, p_{\text {two-tailed }}=0.04\right)$. Similar positive correlations were observed between listening span and $K_{i}$ values from the left putamen $\left(r_{(11)}=0.54, p_{\text {two-tailed }}=0.089\right)$, from the right caudate nucleus $\left(r_{(11)}=0.51, p_{\text {two-tailed }}=0.1\right)$ and 


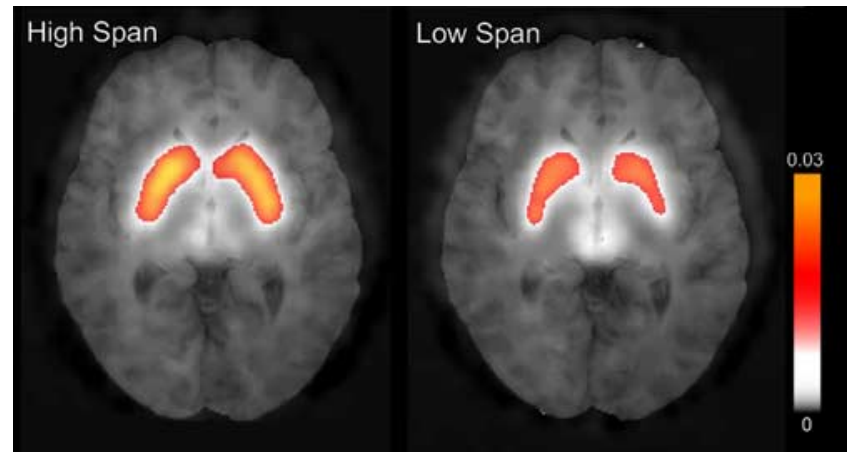

Figure 2. The mean raw axial (MR coregistered) whole-brain FMT PET $K_{i}$ images from the high-span group (left) and from the low-span group (right) overlaid on a normalized MR image. Data represent $K_{i}$ values. The right is right according to neurological conventions.

from the right putamen $\left(r_{(11)}=0.45, p_{\text {two-tailed }}=0.17\right)$, but these did not reach significance.

Supplemental analyses revealed that there were no significant (Pearson's $r$ ) correlations between $K_{i}$ values from any of the four ROIs and performance on any of the other neuropsychological tests $\left(\right.$ all $r_{(11)}$ values $<0.01$, all $p$ values $>0.6$; MoCA, all $r_{(11)}$ values $<0.4$, all $p$ values $>0.2$; Stroop interference score, all $r_{(11)}$ values $<0.02$, all $p$ values $>0.7$; spatial span, all $r_{(10)}$ values $<0.4$, all $p$ values $>0.24$ (one spatial span dataset missing); forward digit span, $r_{(11)}$ values $<0.35$, all $p$ values $>0.3$; verbal fluency, all $r_{(11)}$ values $<0.06$, all $p$ values $>0.8$; WCST, percentage of perseverative errors, all $r_{(8)}$ values $<-0.6$, all $p$ values $>0.1$; WCST, percentage of nonperseverative errors, all $r_{(8)}$ values $<-0.6$, all $p$ values $>0.1$; three WCST datasets missing; all $p$ values two tailed).

In Figure 2, we show the mean raw axial (MR coregistered) whole-brain FMT PET $K_{i}$ image from the high-span group (left panel) and the low-span group (middle). ANOVA revealed significantly lower $K_{i}$ values in the low-span group than in the highspan group for the left caudate nucleus $\left(F_{(1,9)}=5.8, p_{\text {two-tailed }}=\right.$ $0.04)$ and the left putamen $\left(F_{(1,9)}=5.0, p_{\text {two-tailed }}=0.05\right)$. Differences in terms of values from the right-sided ROIs did not reach significance (right caudate nucleus, $F_{(1,9)}=2.9$; right putamen, $\left.F_{(1,9)}=2.1\right)$.

\section{Discussion}

Here, we demonstrate for the first time that working memory capacity as measured with the listening span test is associated with DA synthesis capacity in the striatum; a significant positive correlation was found between DA synthesis capacity in the left caudate nucleus and listening span (Salthouse and Babcock, 1991), indicating that subjects with low working memory capacity have low DA synthesis rates in the striatum, whereas subjects with high working memory capacity have high DA synthesis rates in the striatum. DA synthesis capacity was also lower for low-span subjects in the left putamen, the right caudate nucleus and the right putamen, but these effects did not reach significance, with the left lateralization of the effect possibly reflecting the verbal nature of the task. These data provide empirical evidence for the pervasive, but hitherto untested hypothesis that the dependency of dopaminergic drug effects on baseline working memory capacity reflects differential baseline levels of DA function. For example, the $\mathrm{D}_{2}$ receptor agonist bromocriptine reduced perseverative responding on the WCST in low-span subjects, but increased perseverative responding on the WCST in high-span subjects (Kimberg et al., 1997). Similarly, bromocriptine improved atten- tional switching on a working memory paradigm in low-span subjects but, if anything, impaired switching in high-span subjects (Cools et al., 2007). These latter contrasting effects of bromocriptine on switching difficulty were accompanied by opposite effects on neural activity in the striatum, as measured with functional magnetic resonance imaging; bromocriptine potentiated task-related striatal activity in low-span subjects, but if anything attenuated striatal activity in high-span subjects. These effects were interpreted to reflect differential baseline levels of DA function in the striatum (Cools et al., 2007). The present study provides direct evidence for this hypothesis and confirms that working memory capacity predicts baseline levels of DA synthesis in the striatum.

A significant association between listening span and striatal dopamine synthesis capacity did not extend to other tests such as the spatial span test. Based on recent theoretical models (Frank et al., 2001), we speculate that this specificity reflects disproportionate sensitivity to changes in striatal dopamine of listening span performance, which, unlike the other tests, requires the rapid updating of currently relevant representations in working memory. Performance on, for example, the spatial span test depends more readily on the stable maintenance, rather than the rapid updating, of those representations, which may implicate frontal rather than striatal dopamine. The hypothesis that performance on other working memory tests are also associated with dopamine synthesis capacity is consistent with a recent observation that performance on the two-back working memory task correlated with the degree of task-related dopamine displacement from the $\mathrm{D}_{2}$ receptor as measured with $\left[{ }^{11} \mathrm{C}\right] \mathrm{FLB} 457$ (a highaffinity radioligand for extrastriatal $\mathrm{D}_{2}$-like receptors) PET (Aalto et al., 2005). Indeed, the degree of task-related dopamine displacement may well depend on dopamine synthesis capacity.

Until now, evidence for an optimal level of DA comes primarily from animal studies investigating the effects of $\mathrm{DA}_{1}$ receptor stimulation in the PFC, with low doses improving, but high doses impairing working memory performance (Zahrt et al., 1997; Arnsten, 1998; Granon et al., 2000). An important implication of the present study is that a similar mechanism must exist for DA $\mathrm{D}_{2}$ receptor stimulation in the striatum of humans, who exhibit opposite behavioral effects as a function of working memory capacity after administration of relatively selective $D_{2}$ receptor agents [such as bromocriptine (Kimberg et al., 1997; Gibbs and D'Esposito, 2005; Cools et al., 2007), cabergoline (Frank and O'Reilly, 2006), and haloperidol (Frank and O'Reilly, 2006)]. Indeed, $\mathrm{D}_{2}$ receptors are much more abundant in the striatum than in the PFC (Camps et al., 1989). The conclusion that an optimal level of DA function exists not only in the PFC, but also in the striatum, is also consistent with a recent observation that infusion into the (ventral) striatum of a low, but not a high DA receptor agonist dose improved accuracy on an attentional choice reaction time task (Pezze et al., 2007).

Although the present study indicates that listening span reflects striatal DA synthesis capacity, it should be noted that it does not directly elucidate the precise pharmacological mechanism underlying the contrasting effects of $\mathrm{D}_{2}$ receptor agents. One possibility is that a reduction in DA synthesis induces supersensitivity and/or increased (upregulated) density of striatal DA receptors, and thus greater sensitivity to the effects of DA $\left(D_{2}\right)$ receptor agents. This hypothesis can account for the observation that low-span subjects are disproportionately sensitive not only to the effects of $\mathrm{DA} \mathrm{D}_{2}$ receptor agonists, but also to those of DA $\mathrm{D}_{2}$ receptor antagonists, such as haloperidol (Frank and O'Reilly, 2006), and can be tested directly using PET imaging with ligands 
such as the $\mathrm{DA} \mathrm{D}_{2}$ receptor antagonists $\left[{ }^{11} \mathrm{C}\right]$ raclopride or $\left[{ }^{18} \mathrm{~F}\right]$ fallypride.

Intriguingly, the relationship between baseline working memory capacity and DA receptor stimulation with the mixed $D_{1} / D_{2}$ receptor agonist pergolide is opposite to that seen for the relatively selective $D_{2}$ receptor agents. In contrast to bromocriptine, administration of pergolide improved working memory performance in high-span subjects, while impairing it in low-span subjects (Kimberg and D'Esposito, 2003; Gibbs and D'Esposito, 2006). This implies that administration of pergolide improves performance in subjects with high DA synthesis capacity in the striatum, but impairs it in subjects with low DA synthesis capacity in the striatum. The apparent discrepancy between the effects of pergolide and bromocriptine may reflect differential selectively of the drugs for $D_{1}$ and $D_{2}$ receptors respectively and the resulting differential (frontal versus striatal) site of modulation. Specifically, the effects of pergolide may reflect modulation of DA in the PFC, where $\mathrm{D}_{2}$ receptors are less abundant, whereas the effects of selective $D_{2}$ receptor agents may reflect a modulation of DA in the striatum. The opposite relationships between working memory capacity, which we demonstrate is associated with striatal DA synthesis, and DA receptor stimulation with pergolide and bromocriptine may thus reflect the known reciprocal relationship between DA in the PFC and DA in the striatum (Pycock et al., 1980). This hypothesis is consistent with the behaviorally selective effects of pergolide on working memory maintenance (Kimberg and D'Esposito, 2003) and those of bromocriptine on set shifting (Kimberg et al., 1997; Cools et al., 2007), particularly given that these two processes have been hypothesized to depend on DA $\left(D_{1}\right.$ receptor function) in the PFC and $D A\left(D_{2}\right.$ receptor function) in the striatum respectively (Crofts et al., 2001; Frank et al., 2001; Bilder et al., 2004; Seamans and Yang, 2004; Cools et al., 2007). This proposal needs to be tested in future studies with neurochemical PET imaging methods that allow the direct comparison of $\mathrm{DA} \mathrm{D}_{1}$ receptor function in the PFC (e.g., using the ligand $\left[{ }^{11} \mathrm{C}\right] \mathrm{NNC} 112$ or $\left[{ }^{11} \mathrm{C}\right] \mathrm{SCH} 23390$ ) (both dopamine $\mathrm{D}_{1}$ receptor antagonist ligands) with $\mathrm{DA}_{2}$ receptor function in the striatum.

The present results were obtained in a relatively small sample of female volunteers. The significance of both the group difference as well as the continuous measure suggests that the difference will hold in larger groups, to be tested in future studies. The inclusion of females only may have affected variability in baseline levels of dopaminergic neurotransmission, which likely depend on estrogen levels. Future work should address directly the relationship between dopamine, working memory and menstrual cycle and will help to determine whether the present results are trait and/or state dependent.

\section{References}

Aalto S, Bruck A, Laine M, Nagren K, Rinne J (2005) Frontal and temporal dopamine release during working memory and attention tasks in healthy humans: a positron emission tomography study using the high-affinity dopamine D2 receptor ligand [11C]FLB 457. J Neurosci 25:2471-2477.

Alexander G, DeLong M, Stuck P (1986) Parallel organisation of functionally segregated circuits linking basal ganglia and cortex. Annu Rev Neurosci 9:357-381.

Arnsten AFT (1998) Catecholamine modulation of prefrontal cortical cognitive function. Trends Cogn Sci 2:436-446.

Bäckman L, Ginovart N, Dixon RA, Wahlin TB, Wahlin Å, Halldin C, Farde L (2000) Age-related cognitive deficits mediated by changes in the striatal dopamine system. Am J Psychiatr 157:635-637.

Beck AT, Ward CH, Mendelson M, Mock J, Erbaugh J (1961) An inventory for measuring depression. Arch Gen Psychiatr 11:561-571.
Benton AL (1968) Differential behavioral effects in frontal lobe disease. Neuropsychologia 6:53-60.

Bilder R, Volavka K, Lachman H, Grace A (2004) The catechol-Omethyltransferase polymorphism: relations to the tonic-phasic dopamine hypothesis and neuropsychiatric phenotypes. Neuropsychopharmacology 29:1943-1961.

Brozoski TJ, Brown R, Rosvold HE, Goldman PS (1979) Cognitive deficit caused by regional depletion of dopamine in the prefrontal cortex of rhesus monkeys. Science 205:929-931.

Camps M, Cortes R, Gueye B, Probst A, Palacios J (1989) Dopamine receptors in human brain: autoradiographic distribution of D2 sites. Neurosci 28:275-290.

Cools R, Barker RA, Sahakian BJ, Robbins TW (2001) Enhanced or impaired cognitive function in Parkinson's disease as a function of dopaminergic medication and task demands. Cereb Cortex 11:1136-1143.

Cools R, Sheridan M, Jacobs E, D’Esposito M (2007) Impulsive personality predicts dopamine-dependent changes in frontostriatal activity during component processes of working memory. J Neurosci 27:5506-5514.

Crofts HS, Dalley JW, Van Denderen JCM, Everitt BJ, Robbins TW, Roberts AC (2001) Differential Effects of 6-OHDA lesions of the frontal cortex and caudate nucleus on the ability to acquire an attentional set. Cereb Cortex 11:1015-1026.

Daneman M, Carpenter P (1980) Individual differences in working memory and reading. J Verbal Learning Verbal Behav 19:450-466.

DeJesus O, Endres C, Shelton S, Nickles R, Holden J (1997) Evaluation of fluorinated $\mathrm{m}$-tyrosine analogs as PET imaging agents of dopamine nerve terminals: comparison with 6-fluoroDOPA. J Nucl Med 38:630-636.

Floresco S, Phillips AG (2001) Delay-dependent modulation of memory retrieval by infusion of a dopamine D1 agonist into the rat medial prefrontal cortex. Behav Neurosci 115:934-939.

Frank M, Loughry B, O’Reilly R (2001) Interactions between frontal cortex and basal ganglia in working memory: a computational model. Cogn Affect Behav Neurosci 1:137-160.

Frank MJ, O’Reilly RC (2006) A mechanistic account of striatal dopamine function in human cognition: psychopharmacological studies with cabergoline and haloperidol. Behav Neurosci 120:497-517.

Fuster J (1989) The prefrontal cortex. New York: Raven.

Gibbs SE, D'Esposito M (2005) Individual capacity differences predict working memory performance and prefrontal activity following dopamine receptor stimulation. Cogn Affect Behav Neurosci 5:212-221.

Gibbs SE, D’Esposito M (2006) A functional magnetic resonance imaging study of the effects of pergolide, a dopamine receptor agonist, on component processes of working memory. Neuroscience 139:359-371.

Goldman-Rakic P (1995) Cellular basis of working memory. Neuron 14:477-485.

Granon S, Passetti F, Thomas KL, Dalley JW, Everitt BJ, Robbins T (2000) Enhanced and impaired attentional performance after infusion of D1 dopaminergic receptor agents into rat prefrontal cortex. J Neurosci 20:1208-1215.

Grant DA, Berg EA (1948) A behavioural analysis of degree of reinforcement and ease of shifting to new responses in a Weigl-type card sorting problem. J Exp Psychol 38:404-411.

Jordan S, Eberling J, Bankiewicz K, Rosenberg D, Coxson P, VanBrocklin H, O'Neil J, Emborg M, Jagust W (1997) 6-[ ${ }^{18}$ F]fluoro-L-m-tyrosine: metabolism, positron emission tomography kinetics, and 1-methyl-4phenyl-1,2,3,6-tetrahydropyridine lesions in primates. Brain Res 750:264-276.

Kimberg D, D'Esposito M (2003) Cognitive effects of the dopamine receptor agonist pergolide. Neuropsychologia 41:1020-1027.

Kimberg DY, D'Esposito M, Farah MJ (1997) Effects of bromocriptine on human subjects depend on working memory capacity. NeuroReport 8:3581-3585.

Klein G, Teng X, Jagust W, Eberling J, Acharya A, Reutter B, Huesman R (1997) A methodology for specifying PET VOI's using multimodality techniques. IEEE Trans Med Imaging 16:405-415.

Lammertsma A, Hume S (1996) Simplified reference tissue model for PET receptor studies. NeuroImage 4:153-158.

Mattay V, Goldberg T, Fera F, Hariri A, Tessitore A, Egan M, Kolachana B, Callicot J, Weinberger D (2003) Catechol-O-methyltransferase Val ${ }^{158}$ -met genotype and individual variation in the brain response to amphetamine. Proc Natl Acad Sci USA 100:6186-6191.

Mattay VS, Callicot JH, Bertolino A, Heaton I, Frank JA, Coppola R, Berman 
KF, Goldberg TE, Weinberger DR (2000) Effects of dextroamphetamine on cognitive performance and cortical activation. NeuroImage 12:268-275.

Mehta M, Calloway P, Sahakian B (2000) Amelioration of specific working memory deficits by methylphenidate in a case of adult attention deficit/ hyperactivity disorder. J Psychopharm 14:299-302.

Milner B (1971) Interhemispheric differences and psychological processes in man. Br Med Bull 27:272-277.

Namavari M, Satyamurthy N, Phelps M, Barrio J (1993) Synthesis of $6-[18 \mathrm{~F}]$ and 4-[18F]fluoro-L-m-tyrosines via regioselective radiofluorodestannylation. Appl Radiat Isot 44:527-536.

Nasreddine Z, Phillips N, Bédirian V, Charbonneau S, Whitehead V, Collin I, Cummings J, Chertkow H (2005) The Montreal Cognitive Assessment (MoCA): a brief screening tool for mild cognitive impairment. J Am Geriatr Soc 53:695-699.

Nelson HE (1982) National Adult Reading Test (NART) test manual. Windsor, UK: NFER-Nelson.

Patlak C, Blasberg R (1985) Graphical evaluation of blood-to-brain transfer constants from multiple-time uptake data. Generalizations. J Cereb Blood Flow Metab 5:584-590.

Patton J, Stanford M, Barratt E (1995) Factor structure of the Barratt impulsiveness scale. J Clin Psychol 51:768-774.

Pezze MA, Dalley JW, Robbins TW (2007) Differential roles of dopamine D1 and D2 receptors in the nucleus accumbens in attentional performance on the five-choice serial reaction time task. Neuropsychopharmacology 32:273-283.

Phillips A, Ahn S, Floresco S (2004) Magnitude of dopamine release in me- dial prefrontal cortex predicts accuracy of memory on a delayed response task. J Neurosci 14:547-553.

Pycock CJ, Kerwin RW, Carter CJ (1980) Effect of lesion of cortical dopamine terminals on subcortical dopamine receptors in rats. Nature 286:74-77.

Salthouse T, Babcock R (1991) Decomposing adult age differences in working memory. Dev Psychol 27:763-776.

Sawaguchi T, Goldman-Rakic PS (1991) D1 dopamine receptors in prefrontal cortex: involvement in working memory. Science 251:947-950.

Seamans JK, Yang CR (2004) The principal features and mechanisms of dopamine modulation in the prefrontal cortex. Prog Neurobiol 74:1-58.

Stroop J (1935) Studies of interference in serial verbal reactions. J Exp Psychol 18:643-662.

Talairach J, Tournoux P (1988) Co-planar stereotaxic atlas of the human brain: 3-dimensional proportional system: an approach to cerebral imaging. Stuttgart, Germany: Thieme.

Volkow N, Gur R, Wang G, Fowler J, Moberg P, Ding Y, Hitzemann R, Smith G, Logan J (1998) Association between decline in brain dopamine activity with age and cognitive and motor impairment in healthy individuals. Am J Psychiatr 155:344-349.

Wang G, Volkow N, Levy A, Fowler J, Logan J, Alexoff D, Hitzemann R, Schyler D (1996) MR-PET image coregistration for quantitation of striatal dopamine D2 receptors. J Comput Assist Tomogr 20:423-428.

Williams GV, Goldman-Rakic PS (1995) Modulation of memory fields by dopamine D1 receptors in prefrontal cortex. Nature 376:572-575.

Zahrt J, Taylor JR, Mathew RG, Arnsten AFT (1997) Supranormal stimulation of D1 dopamine receptors in the rodent prefrontal cortex impairs spatial working memory performance. J Neurosci 17:8528-8535. 